\title{
Reflexões sobre a produção e o ensino do texto por meio de uma perspectiva enunciativa
}

\author{
Marcos Luiz Cumpri
}

\begin{abstract}
Resumo: Basicamente, este trabalho visa a fomentar as representações das ocorrências abstratas nos tratados da produção e do ensino do texto. Apesar de a linguística textual privilegiar a coesão, a coerência e a correção em detrimento das representações das atividades simbólicas das línguas naturais, traz-se aqui uma reflexão que passa pelo processo cognitivo (sobretudo por algumas considerações sobre o desenvolvimento da linguagem e da construção do sentido) e pela definição de texto enquanto uma sequência de representações conceituais intersubjetivas para chegar ao bojo do que é proposto nessas páginas: a inserção do sujeito e suas percepções socioculturais nas considerações acerca do ensino da escrita.

Palavras-chave: Texto; Ensino; Enunciação; Linguística textual.

Abstract. This paper aims to stimulate the representations of abstract occurrences in the production and teaching of writing. Text linguistics privileges cohesion, coherence and correction over the representations of natural languages symbolic activities. This paper reflects about the cognitive process (in particular language development and the construction of meaning) as well the definition of text as a sequence of intersubjective conceptual representations before presenting the main topic of the paper which is the socio cultural insertion of man and his perceptions about the teaching of writing. Keywords: Text; Teaching; Enunciation; Text linguistics.
\end{abstract}

Introdução

O artigo que aqui apresentamos é o cerceio de uma pesquisa focada na produção textual. Para tal, ancoramo-nos nos pensamentos que norteiam as propostas de Antoine Culioli e seus colaboradores, as quais constituem a teoria das operações predicativas e enunciativas (Tope), uma proposta teórica que visa ao estudo da articulação da linguagem com as línguas naturais por meio de uma aposta radical na indeterminação da linguagem.

Este texto, além de sumariar criticamente alguns dogmas da linguística textual, aponta elucubrações que colocam os processos percorridos pelos estudantes ao lidarem com língua e linguagem no cerne das discussões acerca do ensino da língua. A nossa concepção de sujeito enunciador é uma instância construída juntamente com os processos constitutivos do enunciado. E, dessa forma, embrenhando-nos nesse processo, estaremos acessando a linguagem

*Doutorando. Universidade Estadual Paulista - UNESP - E-mail: marcoscumpri@yahoo.com.br 
e nos inscrevendo em uma discussão genuinamente linguístico-educacional.

Assim, defendemos o trabalho metalinguístico, a abstração, a (re)montagem, a construção e a organização das noções (sistemas representacionais das propriedades físico-culturais ligados à tentativa da elaboração de experiências de cada pessoa por meio dos arranjos léxico-gramaticais) como mecanismos essenciais a serem tratados no ensino da escrita. Trata-se de uma tentativa de inserir o estudante (e seu esforço de materialização das representações mentais) nas discussões acerca da linguística do texto.

\section{O texto: definindo territórios}

A língua é um sistema dinâmico capaz de lidar com todo e qualquer tipo de enunciado e se alicerça em determinados conceitos que fundamentam uma estabilidade teórica ancorada em ajustes linguísticos. Por isso, a produção linguística é também o resultado de um trabalho de montagem e desmontagem dos textos, marcas e valores que, em seguida, têm seus significados construídos e reconstruídos por meio das atividades linguísticas.

Os atos de linguagem são agenciamentos de formas que partem dos mecanismos enunciativos que o constituem. $\mathrm{O}$ valor referencial de um texto não é um dado, mas um construto. E o significado de um enunciado é reverberado por meio de modulações de sentido que dialogam entre si e com um determinado conteúdo predicativo, o qual fornece a espessura dialógica necessária à construção da representação.

Apesar de o texto ser comumente visto como uma elaboração de uma série de frases e tendo uma intenção comunicativa prévia, a definição de Culioli (1973) fornece um ponto de vista mais adequado com uma proposta linguístico-educacional. Para ele, o texto funciona não como transmissão de um conceito de um falante para seu interlocutor, mas como uma sequência de representações que resultam de um conjunto de operações realizadas por um sujeito enunciador que, em uma situação de enunciação (que inclui os interlocutores e um momento), busca constituir um sentido.

Nesse mesmo caminho, o texto - enquanto conjunto de colocalizações de enunciados - coincide com o que podemos chamar de constituição de sentidos, os quais são conceitos, noções oriundas das vivências do homem. Logo, o texto oferece uma visão referencial, contextual e situacional, colocando em 
cena valores extralinguísticos (o cultural) associados ao intralinguístico por meio das operações que constituem o enunciado.

\section{Cognição: a primeira preocupação educacional}

Sendo a faculdade da linguagem o eixo condutor das pesquisas em ciência cognitiva, há certo consenso entre psicólogos, linguistas e neurologistas no tocante à averiguação dos diversos processos mentais que envolvem a atividade linguística, especialmente os processos pelos quais os sujeitos desenvolvem a linguagem. Para este item, optamos por propalar algumas das reflexões de Whorf ${ }^{2}$ e Bruner ${ }^{3}$ direcionadas à cognição e ao desenvolvimento da linguagem.

Para Whorf, um dos pioneiros entre os que olharam para o papel da linguagem na cognição, os processos linguísticos originam-se de operações cognitivas localizadas no centro da atividade conceitual humana e tais processos são elaborações secundárias que desenvolvem os dados, os quais já são perceptualmente estruturados e fomentadores de uma base comum para a atividade de referenciação.

O linguista ainda postula a existência de configurações universais de experiência, às quais são aplicáveis modelos linguísticos de classificação e categorização. Ele propõe também a distinção do que ele chama de isolamentos de experiência de isolamentos de significado: enquanto os primeiros seriam abstraídos dos sentidos já desenvolvidos, os segundos seriam características da experiência envolvida na construção do significado com a possibilidade de serem cultura, social ou individualmente adquiridas.

Por fim, para Whorf, a construção de significado corresponde a uma abstração seletiva da experiência de modelos. Ou seja, o material linguístico-expressivo já é uma realidade estruturada construída a partir de modelos psi-

\footnotetext{
${ }^{1}$ A Proposta Curricular de Língua Portuguesa do Estado de São Paulo afirma claramente a aproximação entre enunciado e texto: "o estudo do texto terá ainda como premissa sua inserção em dada situação de comunicação-podendo, dessa forma, ser entendido como sinônimo de enunciado”. (FINI, 2008, p. 46).

${ }^{2}$ Algumas ideias aqui apresentadas acerca do postulado de Whorf foram retiradas do trabalho de Fuchs (1999).

${ }^{3}$ Processo similar ocorreu em relação a alguns apontamentos sobre Bruner, os quais se encontram em Correa (1999)
} 
cofisiológicos igualmente pertencentes ao ser humano, mesmo que as línguas conceitualizem esses dados experienciais de forma diferente uma das outras em suas diferentes culturas.

Dentre os estudiosos da cognição, Jerome Bruner também assume um especial destaque dentro da literatura mais vigente. Para o nosso trabalho, o que talvez se torne mais relevante seja o fato de este psicólogo não separar pensamento e linguagem no que se refere à evolução do homem. Dessa forma, o pensamento se desenvolveria junto à linguagem e dela dependeria intrinsecamente.

Para Bruner, o desenvolvimento intelectual é caracterizado por independência crescente da resposta em relação à natureza imediata do estímulo, e assim o sujeito deve tanto adquirir meios de representar o que ocorre em seu ambiente quanto conservar e recuperar a experiência decorrente da estimulação do meio.

O estudioso ainda coloca os aspectos sociais e culturais no âmago do processo de aprendizagem, pois para ele os sujeitos são seres capazes de construir novos conceitos, os quais são resultados de conhecimentos tanto atuais quanto prévios, e assim eles são hábeis para construir hipóteses fundamentadas em uma estrutura cognitiva.

Bruner ainda encara a aprendizagem enquanto um processo tipicamente categorial, em que a categorização relaciona-se, entre outros, com processos de seleção de informação, geração de proposições e construção e verificação de hipóteses. Dessa forma, o sujeito organiza as informações de acordo com suas categorias, as quais determinam diferentes conceitos. Nesse contexto, o sujeito é ativo e construtor de sua própria aprendizagem e o processo de associações e construções só é possível graças a uma estrutura cognitiva prévia que dá significação e organização às suas experiências.

Encerrando esta seção, vale dizer que a diversidade da linguagem é, de fato, uma das questões teóricas primárias nos tratados de linguística enquanto a ciência que busca apreender a faculdade da linguagem humana por meio da multiplicidade das línguas individuais. Falar da diversidade da linguagem implica, também, falar da construção e da expressão de diferentes representações de mundo - em outras palavras, a atividade cognitiva. 
3. O que não muda e o que poderia mudar no ensino da escrita

A ausência de conteúdo programático, a falta de sistematização dos conhecimentos e a sua deficiência na utilização dessa atividade sempre foram grandes preocupações do professor de língua materna em relação ao ensino da escrita. Os livros didáticos se adéquam à finalidade, à formação moral, ao senso crítico, ao ensino da gramática, à criatividade; mas não chamam a atenção dos alunos para os processos a serem percorridos rumo à construção das significações. O que há na verdade é pouca margem para a reflexão e excesso de aplicação de pré-estruturas textuais que garantem o sucesso da boa escrita.

De acordo com os preceitos mais clássicos da linguística textual, ${ }^{4}$ o texto de qualidade é concebido como aquele cuja leitura se torna fluente e de fácil compreensão por organizar-se de forma coesa e coerente e apresentar-se com uma linguagem adequada ao tema que nele está sendo desenvolvido. Forma e conteúdo ou, como comumente se prefere, significante e significado devem fundir-se em um todo harmonioso. Assim, a esse todo caberá apresentar suas partes devidamente ordenadas e agindo não de modo isolado, cada uma por si, mas de maneira integrada, em função da nova unidade constituída.

Com efeito, um texto será bem articulado enquanto for redigido de modo a conter as qualidades imprescindíveis da coesão, da coerência, da adequação da linguagem e, por extensão, da clareza e da aceitável correção. Em outras palavras, o texto apropriado teria razoável qualidade, ou seja, características de legibilidade e de entendimento decorrentes de uma estrutura coesa e coerente e que apresente uma linguagem adequada ao tema em si.

Do lado contrário, um dito texto ruim é aquele que se ausenta da tradição, isto é, de práticas que levem à produção de textos e de condições necessárias de conhecimento e de incentivo para a confecção do mesmo. Dito de outra forma, seria um texto que se apresenta de forma ilegível, incompreensível e ilógica pela falta de coesão, de coerência e por uma linguagem não adequada ao tema e à situação propostos. Tratar-se-ia de um compilado de palavras que não se sustenta como estrutura linguística capaz de transmitir informação.

\footnotetext{
${ }^{4}$ Alguns desses preceitos podem ser encontrados, principalmente, nos trabalhos de Kock (1996), Kock; Travalia (1996) e Charolles (1978) entre outros, os quais apontam os elementos textuais imprescindíveis para a organização do texto. 
Analisando os manuais de ensino encontramos um posicionamento quase que unânime quanto à solução do problema: estabelecer práticas pedagógicas que levem o estudante a redigir um texto que, teoricamente, apresente uma evolução qualitativa quanto à estruturação que inicialmente apresentava, ou seja, um texto mais coeso e mais coerente e, portanto, um bom texto.

A crítica a ser feita é a de que o texto escolar é fomentado por um discurso preestabelecido que as instituições de ensino repassam como modelo pronto, para que, assim, tente-se cumprir uma tarefa quase que mecânica: a de "resolver o problema da redação". Nesse caso, pelo fato de não se dominar as tais técnicas de produção textual e de não se possuir as informações necessárias (bagagem cultural), pela falta de leitura e de estudo sobre o tema que se irá enfocar, o texto constantemente acaba por parecer irreal e descontextualizado.

O que queremos defender é que, aparte deste infindável círculo vicioso que se cria ao redor da produção do texto e conseqüentemente do seu ensino, o estudante (e seus percursos enunciativos rumo à representação de suas percepções físico-psicológicas) deve ser a própria fonte para o seu estudo.

Ressaltamos que em nenhum momento queremos negar que leitura e escrita se complementam em uma relação interdependente, pois nós, estudiosos incansáveis das línguas naturais, bem sabemos que escrever é uma atividade que requer prática constante e aprender língua também requer métodos formais.

Em adição, cremos que o trabalho (esforço metalinguístico) do estudante no sentido de reconhecer e interpretar seu próprio texto torna-se importante ao habilitá-lo para a produção (fala e escuta, redação e leitura) de textos orais e escritos. Em outras palavras, a reflexão que o estudante pode fazer sobre seu próprio texto encerra o mais alto grau da riqueza da linguagem, uma vez que esta teoria tenta teorizar exatamente a reflexão sobre a linguagem

No ensino, o ato da observação deve ser o primeiro caminho para fazer com que o aprendiz de línguas mergulhe no complexo universo da linguagem por acreditarmos que é por meio dos observáveis que se chega à teorização e à conscientização daquilo que está sendo abordado.

Para nós, o termo coerência assume um sentido um pouco diferente daquele da linguística textual clássica, pois, de acordo com Le Goffic (1981), a coincidência exata entre o sujeito que produz e o sujeito que recebe o enunciado é impossível, haja vista que a significação de um enunciado não é palpável e tão pouco mensurável. Assim, coesão e coerência são dois domínios muito 
relativos, pois fica a pergunta: qual o objetivo de uma aula focada na produção do texto? Como fazer então para resolver o ensino do texto? Vejamos o que diz Onofre:
"O objetivo é chamar a atenção do aluno sobre as sutilezas linguísticas que cada situação enunciativa exige, levando-o a perceber tanto a iden- tidade semântica quanto a diferença semântica que podem ser estabe- lecidas a partir de uma cadeia parafrástica." (ONOFRE, 1994, p. 159)

Portanto, aprender língua (e consequentemente as habilidades que constituem esse processo, dentre as quais a escrita e a leitura) é também mergulhar nela para se chegar à linguagem e procurar as propriedades e os processos generalizáveis. E é o empírico que vai nos levar a isso, ao contexto e à situação, pois

"A atividade de produção e de reconhecimento de enunciados se faz sempre entre os sujeitos colocados nas situações às vezes empíricas e ao mesmo tempo ligadas às representações imaginárias do estatuto de alguns sujeitos para remeter ao outro, para remeter a uma sociedade, para remeter ao texto, para remeter àquilo que se poderia chamar de um discurso intertextual, esta espécie de discurso ambiente com os valores que estão ligados às palavras.” (CULIOLI, 2002, p. 92, tradução nossa)

Assim, escrever é organizar experiências de mundo e, dessa forma, o texto não é somente um composto interpretativo, mas um elemento de representação, regulação e referenciação do sujeito que o produz. Nesse sentido, o conhecimento gramatical não assume uma urgência tão ímpar quanto a capacidade de ler, escrever e refletir sobre a linguagem, pois cremos que pensar e agir sobre a construção da significação e do sentido proporcionam escritas melhores.

A criatividade textual é mais uma capacidade de perceber o universo externo do indivíduo que a construção de enunciados inusitados e inéditos, pois é a experiência sociopsicológica a grande fomentadora da criatividade linguística. As representações físico-culturais só são possíveis graças a uma representação interior de memórias associativas, de pensamentos e linguagens simbólicas. 
Com efeito, o estudo do texto focado na reflexão sobre ele (processos constitutivos, percursos enunciativos, atividade parafrástica etc.) estabelece a ponte entre a criatividade e o extralinguístico de um lado e a norma lingüística do outro. E é essa ponte que estimula a utilização de mecanismos linguísticos que, além de atribuírem maior fluência nos atos de escrita, também ativam o potencial de compreensão da funcionalidade desses atos por ativarem a linguagem e trazerem à tona todo seu caráter infinito.

Portanto, ao professor fica a possibilidade de incentivar o aluno a trabalhar a reconstrução do texto por meio da reorganização de períodos e enunciados com base em recursos como o apagamento, o deslocamento, a negação, a interrogação e a inserção de outros elementos linguístico-textuais. Já as questões de gramática, a nosso ver, devem ser elaboradas a partir do texto, pois assim o aluno estará trabalhando, com mais entusiasmo, a partir de conceitos linguísticos sociais. Isso sem contar que é o texto o grande fomentador das manifestações tanto de recursos gramaticais e sintáticos quanto estilísticos de uma dada língua.

Outra maneira interessante de abordar o estudo do texto em sala de aula é, além de explorar as experiências prévias, fazer associações de tais experiências com as atividades textuais. Daí remetemo-nos novamente a um conceito que julgamos fundamental, o de que o texto é o resultado de um trabalho sensível e abstrato que passa obrigatoriamente pela transformação de noções de cunho psicológico, sociológico, cultural e até científico em representações linguísticas.

À parte das reflexões que poderíamos propor como geradoras de discussões que nos levem a aproximar texto e ensino, arriscamos um diálogo crítico com a linguística textual - para a qual, como já dissemos, um texto será bem articulado enquanto for redigido de modo a conter as qualidades imprescindíveis de coesão, coerência, adequação da linguagem e, por extensão, clareza e aceitável correção - tentando mostrar que sujeito, enunciação e situação enunciativa fazem parte de um tripartite indissociável, principalmente no estudo e no ensino do texto, o qual é pura representação dessa relação.

Assim, julgamos que o sucesso da comunicação verbal está também relacionado a questões que concernem às propriedades físico-culturais de cada sujeito e que os recursos linguístico-textuais são o pano de fundo da organização dessas propriedades - em outros termos, as percepções socioculturais.

$\mathrm{Na}$ verdade, a grande impressão que fica é a de que o ato da escrita 
agencia percursos enunciativos bem mais complexos que aqueles que a linguística textual comumente categoriza como coesão, coerência e correção gramatical.

\section{Considerações finais}

Como resultado, tentamos chamar mais a atenção para a relevância do percurso enunciativo do estudante (enquanto um ser dotado de uma cultura de ordem sociopsicológica) na discussão estabelecida no ensino da escrita. O que fica de fundamental é a assunção dos conceitos de língua e linguagem não como comunicação, mas como equilíbrio.

Quisemos registrar, também, que o ato da reflexão acerca da linguagem encerra o mais alto grau de sua riqueza, uma vez que a nossa proposta teórico-metodológica tenta teorizar exatamente esse trabalho e, dessa forma, o ato da observação faz-se um caminho necessário para que o sujeito adentre o complexo universo da linguagem. Em outras palavras, acreditamos que é por meio dos observáveis que se chega à teorização e à conscientização daquilo que está sendo abordado.

Dado o notório esforço que os sujeitos enunciadores fazem com a linguagem ao produzirem e reconhecerem textos, tentamos deixar registrado se não a certeza de que se chega a operações generalizáveis por meio da análise das particularidades, das variáveis e das exceções da língua, pelo menos a intrínseca relação que há entre os ajustes linguísticos realizados pelos sujeitos enunciadores e o processo de construção da significação verbal escrita.

\section{Referências}

CORREA, L. M. S. Language acquisition: a survey of the research of the last thirty years. Delta: Documentação de Estudos em Linguística Teórica e Aplicada, v.15 (n. especial), 1999.

CULIOLI, A. Sur quelques contradictions en linguistique. Communications, $\mathrm{n}$. 20, maio 1973, p. 83-91. 
Marcos Luiz Cumpri

. Transcription du séminaire de D.E.A.: 1975-1976. Paris: Université de Paris VII. D.R.L., 1976.

. Variations sur la linguistique. Paris: KlincKsieck, 2002.

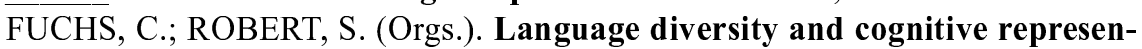
tations. Amsterdã: John Benjamins, 1999.

LE GOFFIC, P. Ambiguïté linguistique et activitè de langage. Paris: Université de Paris VII, 1981.

ONOFRE, M. B. A indeterminação na linguagem: inconsciência e manipulação. 1994. Dissertação (Mestrado em Linguística e Língua Portuguesa) - Faculdade de Ciências e Letras, Unesp, Araraquara, 1994.

FINI, Maria Inês (Coord.). Proposta curricular do Estado de São Paulo: língua portuguesa. São Paulo: SEE, 2008.

REZENDE, L. M. Léxico e gramática: aproximação de problemas linguísticos com educacionais. Tese (Livre-docência). Faculdade de Ciências e Letras, Unesp, Araraquara, 2000.

Recebido para publicação em 29 de maio de 2009. Aceito para publicação em 03 de março de 2010. 